\title{
The impairment of the Growth Hormone/Insulin-like growth factor 1 (IGF-1) axis in heart failure: A possible target for future therapy
}

\author{
Lucrezia Piccioli1*, Michele Arcopinto2*, Andrea Salzano1,3, Roberta D'Assante4, \\ Alessandra Schiavo1, Francesca M. Stagnaro1, Anna Lombardi1, Veronica Panicara1, \\ Pietro Valente1, Giuseppe Vitale5, Filippo M. Sarullo5, Francesco Giallauria1, \\ Alberto M. Marra4 \\ 1 Department of Translational Medical Sciences, Federico II University, Naples, Italy \\ 2 Emergency Department, AORN “A. Cardarelli”, Naples, Italy \\ 3 Department of Cardiovascular Sciences and NIHR Leicester Biomedical Research Centre, \\ University of Leicester, Glenfield Hospital, Leicester, UK \\ 4 IRCCS SDN, Naples, Italy \\ 5 Cardiovascular Rehabilitation Unit, Buccheri La Ferla Fatebenefratelli Hospital, Palermo, Italy \\ * These authors equally contributed to the work
}

\begin{abstract}
Hormonal abnormalities are quite common in chronic heart failure (CHF). The most studied hormonal axis in CHF is the impairment of Growth Hormone (GH)/Insulin Growth Factor-1(IGF-1), which in turn is defined either by a blunted response to $\mathrm{GH}$ stimulation test or low serum IGF-1 values. Several independent groups reported that the presence of an abnormal GH/IGF-1 status in CHF is associated with a more severe disease, impaired functional capacity and reduced Survival rates. After the first encouraging results, double -blind controlled trials showed a neutral effect of the $\mathrm{GH}$ administration in patients. However, further studies reported positive results, when a GH-therapy is implemented only in those patients presenting a GH deficiency (replacement therapy).
\end{abstract}

Corresponding author: Dr. Alberto M. Marra, IRCCS SDN, Via Gianturco 131, 80147 Napoli, Italy. Tel/Fax: +39.081 .8907452 .

E-mail: alberto_marra@hotmail.it

Key words: Chronic heart failure; growth hormone; IGF-1; anabolic deficiency; biomarker; outcomes.

Disclosure: The authors have nothing to disclose.

Received for publication: 19 June 2018

Accepted for publication: 30 July 2018

(C) Copyright L. Piccioli et al., 2018

Tipografia PI-ME Editrice, Italy

Monaldi Archives for Chest Disease 2018; 88:975

doi: 10.4081/monaldi.2018.975

This article is distributed under the terms of the Creative Commons Attribution Noncommercial License (by-nc 4.0) which permits any noncommercial use, distribution, and reproduction in any medium, provided the original author(s) and source are credited.

\section{Introduction}

Chronic heart failure (CHF) is a major healthcare issue, being burned by disability, poor outcome and elevated health care costs [1]. Our understanding of CHF has remarkably improved after that the neuro-hormonal model was proposed [1]. This is rooted in ubiquitous over-activation of such patterns (i.e., renin-angiotensin-aldosterone, sympathetic nervous system, inflammatory activation and cytokines), aimed to restoring heart function in a first moment [2,3], but with detrimental effects in the course of the disease [4,5]. The bedrock of current pharmacological therapy of heart failure with reduced ejection fraction (HFrEF) consists of several compounds aimed to blocking the aforementioned molecular pathways, and is associated consistent improvements in terms of morbidity and mortality [6]. Besides the hyperactivation of the aforementioned pathomechanisms, multiple anabolic deficiencies have been consistently described in CHF [7-9]. The impaired activity of Growth Hormone (GH) and its tissue effector Insulin-like Growth Factor 1 (IGF-1) is considered fascinated, given also the possibility of a replacement therapy [10]. This review will be focused on the impairment of GH/IGF-1 axis in CHF, and on the study of GH therapy in CHF.

\section{Effect of GH and IGF-1 on the cardiovascular system}

The GH/IGF-I axis is considered the most powerful anabolic system in nature [11]. It drives post-natal growth by increasing both bone length and density, and muscle mass during life [12]. Moreover, it has important effects on metabolism, mainly on visceral adipose tissue [13]. The actions of IGF-1 are mediated by its own receptor (IGF1R), leading to the activation of the PI3K/Akt signaling pathway, promoting cell growth, inhibiting apoptosis and protecting cells from TNF- $\alpha$ cytotoxicity [10].

Furthermore, it owes a significant impact on the cardiovascular system, by sustaining cardiac growth and performance. IGF-1 leads to an increase of the production of nitric oxide (NO), which in turn leads to a reduction of the systemic vascular resistance [14,15]. Moreover, it 
increases the contractility of cardiomyocytes mainly by increasing intracellular calcium concentration and calcium sensitization of the myofilaments and preserves capillary density. Last but not least, both $\mathrm{GH}$ and IGF-1 are likely to increase protein synthesis in the cardiomyocytes [16]. The reuptake of calcium is also promoted by IGF-1 through the regulation of the sarco-endoplasmic reticulum Ca2+-ATPase (SERCA2), which is involved in diastolic function.

Indeed, animal models of heart failure showed that GH/IGF-1 improves calcium-handling, attenuates left ventricular remodeling and enhances intracellular Akt signaling [17]. In addition, it regulates cardiac growth, cardiomyocyte size and metabolism [10].

\section{Molecular basis of GH/IGF-1 impairment in heart failure}

GH deficiency is a quite common feature of CHF with a recorded prevalence from $32 \%$ to $53 \%$ according to different cohorts [18-20]. The majority of the studies reported also reduced IGF-1 serum values in CHF compared with healthy controls [18,21-23]. Specifically they were remarkably reduced in patients with advanced heart failure [50] or cachexia [24]. GH pulse is down-regulated in CHF and is impaired due to several reasons. A first hypothesis is rooted in hypo-perfusion and reduced oxygen supply, as shown by a proof-of-concept study performed on 25 children with GH deficiency (GHD) undergoing brain MRI. In these report pituitary stalk enhancement were significant impaired in GHD, probably due to a mismatch between arterial perfusion and venous drainage [25]. A primary hypothalamic damage was also theorized by a blunted response to different provocative tests such as Growth Hormone realizing hormone (GHRH), GHRH + Arginine, GHrelated peptides 18. Right heart failure and backward liver congestion, which might occur at the end-stages of CHF, may also impair IGF-1 secretion $[26,27]$ Finally, also background therapy of CHF (such as ACEinhibitors [28] as well as $\beta$-blockers [29]) is likely to modify IGF-1 secretion through a direct inhibitions of IGF-1 signaling.

However, a single pathomechanisms is not able to underline the high reported prevalence of abnormalities of GH/IGF-1 in CHF. Interestingly, these abnormalities are a common finding in several chronic wasting condition characterized by inflammatory activation and cytokine overexpression [11,30-35].

\section{Prevalence and clinical meaning of GH/IGF-1 impairment in CHF}

Evidence arising from a wide panel of population studies indicated how Growth Hormone deficiency (GHD) is associated with impaired cardiac performance, increased peripheral vascular resistance and reduced exercise capacity [10] with a positive correlation between GHD severity and cardiac impairment [36]. Indeed, about $30 \%$ of CHF patients display a GHD [18,19,37]. Recently, Arcopinto et al. demonstrated in $130 \mathrm{CHF}$ undergoing a $\mathrm{GHRH}+$ Arginine provocative test, that the presence of GHD clusters a subgroup of patients with worse clinical status and increased all-cause mortality, higher depression scores, impaired quality of life, presence of left ventricular (LV) remodeling, lower physical performance, and increased NT-proBNP levels38. Interestingly, patients without GHD showed also better right ventricular (RV) function $(+18 \%$ in RV area change, $\mathrm{p}=0.03)$ and lower estimated pulmonary pressures $(-11 \%, \mathrm{p}=0.04)$ [37]. These aforementioned findings might also explain the increased mortality and hospitalization of GHD patients, given the pivotal role of the right heart-pulmonary circulation unit in determining prognosis in CHF [26,38-44]. The assess- ment of GH status might gather important information also in patients presenting acute heart failure exacerbation. Bhandari et al. recently evaluated serum $\mathrm{GH}$ concentrations in 537 patients presenting to the Emergency room for acute heart failure (AHF), and found increased $\mathrm{GH}$ levels in patients who experienced one of prespecified outcome measures (either death or readmission within 1 year) [45]. A further analysis showed that the addition of GH to ADHERE multivariate logistic model (age, sex, urea, heart rate, and systolic blood pressure), and to ADHERE model + NTproBNP lead to a significant reclassification improvement of both the prognostic scores [45].

With regards to IGF-1 levels, discrepancies were reported among several studies published by independent gorups. Broglio et al. [18,46] reported low IGF-1 levels in patients with systolic left ventricle (LV) dysfunction as well as bunted response to GHRH. Anker et al. [24] evaluated the GH/IGF-1 axis in cachectic and non-cachectic patients with advanced heart failure, showing that the first group was characterised by a pattern of $\mathrm{GH}$ resistance (high GH with low IGF-1). Patients with CHF in NYHA class I and II displayed elevated IGF-1 levels ( $\mathrm{p}=0.005$ vs control subjects), whereas patients with more severe disease (NYHA classes III and IV) had values comparable to healthy controls as reported by Al-Obaidi [47] supporting the speculation that IGF-1 rises at the initial stages of the disease in order to compensate and restore the heart function at a para-physiological level. On the other hand, as the illness proceeds a condition of impaired IGF-1 secretion up to a frank state of $\mathrm{GH}$ resistance may be present [24].

The utmost clinical meaning of low IGF-1 levels in CHF is supported by a consistent body of evidence. Indeed, IGF-I deficiency is associated with inflammatory activation, endothelial dysfunction and a consistent impairment of skeletal muscle performance [22]. Furthermore, a condition of low serum IGF-1 levels is also associated with worse outcomes, as demonstrated by several independent groups [10,23,45,48,49]. Interestingly, a landmark study performed by Jankowska and co-workers showed that the concomitance of more than one hormonal deficiencies (IGF-1, DHEA-S, testosterone) was an independent predictor of mortality in men with HF, shedding lights on the interplay among coexisting anabolic deficiencies [21].

The evaluation of IGF-1 might be helpful not only in the CHF phenotype with reduced ejection fraction (HFrEF) but also in heart failure with preserved ejection fraction (HFpEF). Salzano et al. reported lower IGF-1 and higher GHD in HFrEF than HFpEF [50]. Even if lower than in HFrEF, the prevalence of hormone deficiency (HD) in HFpEF was remarkable, considering that more than half of HFpEF had at least 1 hormone deficiency. In this study a major prevalence of atrial fibrillation (AF) in HFpEF was recorded, as expected [51,52]. However, the small sample size did not allow any further investigation regarding the occurrence of AF in patients with hormonal deficiencies and HFpEF. The aforementioned evidences suggest that IGF-1 might be a useful and quick assessable biomarker for the in clinical daily practice, useful for risk stratification and identification a subgroup of patients requiring a more aggressive therapy. Table 1 summarizes the studies evaluating GH/IGF-1 axis in cohorts of patients affected by CHF.

\section{GH therapy in heart failure}

Experimental studies reported beneficial effects associated with $\mathrm{GH}$ administration on cardiac function, peripheral vascular resistance, and survival [53-55]. In these regards, early treatment of large myocardial infarction with $\mathrm{GH}$ reduces pathologic $\mathrm{LV}$ remodeling and improves $\mathrm{LV}$ function [56]. However, the translation of these results in clinical studies did not lead to unequivocal results. After an initial enthusiasm arising from a wide number of preliminary experiences with open- 
Table 1. Summary of studies on GH/IGF-1 axis as biomarker in heart failure.

\begin{tabular}{|c|c|c|c|}
\hline 1st Author & n & Cut-offs & Main findings \\
\hline \multicolumn{4}{|c|}{ Studies on IGF-1 } \\
\hline Niebauer [22] & 52 & Lowest level normal subject & $\begin{array}{l}\text { Reduced skeletal muscle function, increased TNF- } \alpha \text {, CS/ DHEA, } \\
\text { NAdr }(+49 \%) \text { and Adr }(+136 \%) \text { in patients with low IGF-1 }(<104 \mathrm{ng} / \mathrm{ml})\end{array}$ \\
\hline Anker [24] & 72 & Comparison among groups. No cut-off used & $\begin{array}{l}\text { Cachectic patients showed an increase of total serum GH and a } \\
\text { decrease of GHBP compared with non-cachectic patients }\end{array}$ \\
\hline Al-Obaidi [47] & 24 & Comparison among groups. No cut-off used & $\begin{array}{l}\text { Elevated IGF-1 levels in patients with NYHA class I-II but not } \\
\text { in NYHA class III-IV }\end{array}$ \\
\hline Jankowska [21] & 208 & 10th percentile of a healthy subjects' population & $\begin{array}{l}\text { IGF-1 levels prognostic markers of mortality in multivariable models } \\
\text { when adjusted for established prognostic factors }\end{array}$ \\
\hline Petretta [49] & 82 & Log IGF-I/GH <3.45 & Low IGF-I/GH ratio independently predicts all-cause mortality \\
\hline Andreassen [79] & 194 & Lower quartile of IGF-1 & $\begin{array}{l}\text { No relevant association between IGF-1 and baseline cardiac status } \\
\text { nor prognosis }\end{array}$ \\
\hline Watanabe [48] & 142 & Log IGF1/IGFBP3 less than median value & $\begin{array}{l}\text { Low IGF-1/IGFBP3 associated with increased rates of all-cause } \\
\text { mortality, cardiac death, and a composite of cardiac death } \\
\text { and re-hospitalization }\end{array}$ \\
\hline Arcopinto [23] & 207 & $\begin{array}{l}\text { IGF-1 } \leq 122 \mathrm{ng} / \mathrm{ml} \text { (derived from a ROC } \\
\text { curved analysis) }\end{array}$ & Low IGF-1 levels independently predict all-cause mortality \\
\hline Faxen [80] & 164 & Age- standardized scores of IGF-1 & $\begin{array}{l}\text { Higher IGF-1 in HFpEF than HFpEF with similar IGF-BP } 1 \text { IGF-1 } \\
\text { predicts mortality in HFrEF but not in HFpEF }\end{array}$ \\
\hline \multicolumn{4}{|c|}{ Studies on GH } \\
\hline Bhandari [45] & 537 & $\begin{array}{l}\text { GH concentration } 0.11 \mathrm{ng} / \mathrm{mL} \text { and } 1.22 \mathrm{ng} / \mathrm{mL} \\
\text { (based on previous population studies) }\end{array}$ & $\begin{array}{l}\text { GH levels independently predicted } 1 \text { year-outcome in HFrEF } \\
\text { and increased prognostic information over the ADHERE score } \\
\text { and NT-proBNP }\end{array}$ \\
\hline Arcopinto [37] & 130 & $\begin{array}{l}\text { Positivity to GHRH + Arginine test } \\
\text { and BMI-adjusted cut-offs }\end{array}$ & $\begin{array}{l}\text { GHD patients had impaired functional capacity, LV remodeling, } \\
\text { RV performance, elevated NT-proBNP levels and increased } \\
\text { all-cause mortality }\end{array}$ \\
\hline
\end{tabular}

Table 2. Studies on GH administration/replacement in chronic heart failure.

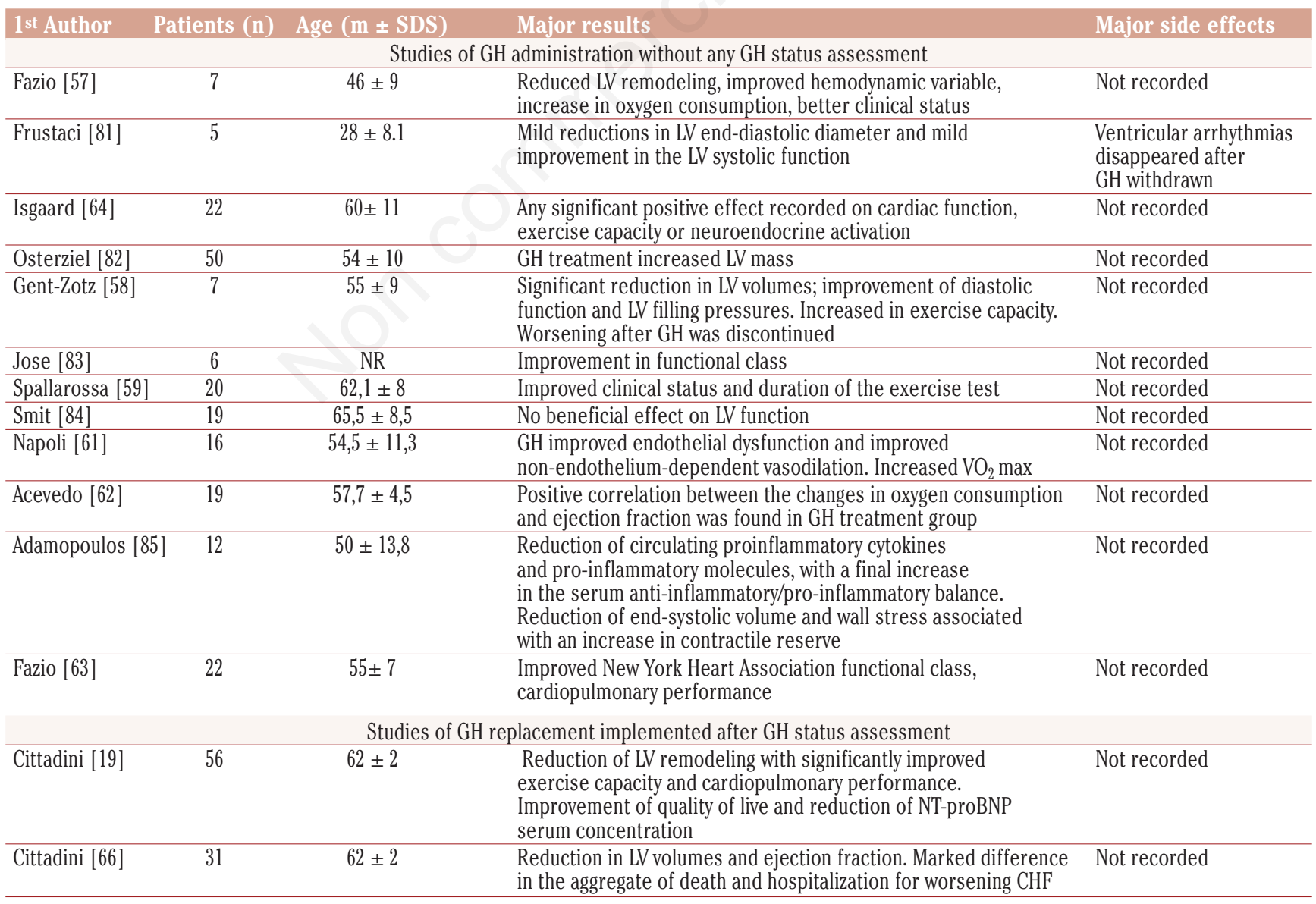

GH: growth hormone; m: mean; SDS: standard deviation; $\mathrm{LV}$ : left ventricle; $\mathrm{VO}_{2}$ max: peak oxygen consumption; NR: not reported; NT-proBNP: n-terminal fragment of the brain natriuretic peptide; $\mathrm{CHF}$ : chronic heart failure. 
labeled pilot studies [57-63], two larger randomized controlled clinical trials $[60,64]$ ended with neutral results. These inconsistent results might be explicated by several reasons: a different study duration, the insufficient target dose, the use of inadequate end-points and the lack of GH status-assessment [65]. Interestingly, a post-hoc analysis of a double-blind placebo-controlled study of $\mathrm{GH}$-administration, those patients who significantly increased IGF-1 due to GH administration displayed a significant improvement of left ventricle systolic function, whereas those without IGF-1 increase did not experienced any improvement [60]. This led to the speculation that GH should be probably administered only in those patients with an impairment of GH/IGF-1 status. Furthermore, GH therapy should not be administered in endstage $\mathrm{CHF}$ patients, which are probably already in a $\mathrm{GH}$ resistance state [24]. Given this magnitude, our group implemented a randomized, single-blind controlled trial, aimed in comparing the effect of $\mathrm{GH}$ replacement therapy in CHF with concomitant GH deficiency [19]. In this study only patients with CHF and a positive GHRH + arginine provocative test were enrolled [19]. We recorded in the group treated with $\mathrm{GH}$ a net improvement of quality of life score (Minnesota living with heart failure questionnaire decreased from $46 \pm 5$ to $38 \pm 4$; $\mathrm{p}<0.01$ ), LV systolic function ( $\mathrm{LV}$ ejection fraction improved from $34 \pm 2$ to $36 \pm 2 \%$; $\mathrm{p}<0.01$ ), peak oxygen uptake (from $12.9 \pm 0.9$ to $14.5 \pm 1 \mathrm{ml} / \mathrm{kg} \cdot \mathrm{min}$, $\mathrm{p}<0.01)$ a decrease of circulating $\mathrm{N}$-terminal pro-brain natriuretic peptide levels (from $3201 \pm 900$ to $2177 \pm 720 \mathrm{pg} / \mathrm{ml}$; $\mathrm{p}<0.006$ ), while no relevant changes were observed in the control group19. After these encouraging results, we decided to prolong this study to a 4-year follow up [66]. After a 4-years follow-up, GH replacement therapy was still associated with $\mathrm{LV}$ reverse remodeling (increase of $\mathrm{LV}$ ejection fraction from $10 \pm 3$ in the treated group $v s-2 \pm 5 \%$ in the control group, p:0.001), end a dramatic increase in peak VO2 (treatment effect of $7.1 \pm 0.7$ in the treated group $v s-1.8 \pm 0.5 \mathrm{ml} / \mathrm{kg}$. $\mathrm{min}$ in control group, $\mathrm{p}<0.01)$. A marked difference in the aggregate of death and hospitalization for worsening CHF in replacement therapy arm was also recorded (31 events in the control group $v s 17$ in the $\mathrm{GH}$ treated patients) [66]. Of note a significant correlation between IGF-1 serum levels and peak V02 was found ( $r: 0.59 ; \mathrm{p}<0.05)$. Notwithstanding the well-described negative effects of $\mathrm{GH}$ administration on glycemic control, no worsening in glycosylated hemoglobin were reported in this study [66]. in However, the usefulness of $\mathrm{GH}$ replacement therapy must be still proved in robust double-blind placebo-controlled trial. Table 2 summarizes the studies evaluating $\mathrm{GH}$ administration/replacement in $\mathrm{CHF}$.

\section{Future prospective and conclusions}

The interplay between hormones and the cardiovascular system is complex [11,66,67-76]. The importance of the somatotropic axis in cardiovascular homeostasis were extensively described in the last 3 decades. Chronic Heart Failure represents a prototype of the interaction between GH/IGF-1 pathway in a chronic cardiovascular impairment status [77]. Indeed, according with most of studies, patients with an impaired GH/IGF-1 status are affected by a more aggressive disease, limited functional and exercise capacity, overexpression of neurohormonal peptides, a more severe left ventricle remodeling and poorer outcomes (mortality and hospitalization). For this reason, a prospective multicenter clinical registry aimed in investigate the impact of multiple and concomitant Anabolic Deficiencies (including therefore also $\mathrm{GH}$ and IGF-1 assessment, testosterone, insulin resistance, thyroid, etc.) on clinical status, exercise capacity, neurohormonal activation, left ventricle architecture and function, quality of life, hospitalization and mortality rate in patients affected by CHF was implemented recently and was named T.O.S.C.A (Trattamento Ormonale nello Scompenso
CArdiaco), whose preliminary results will be available within few months [8,78].

Furthermore, several open-label studies reported the potential beneficial effects of $\mathrm{GH}$ replacement therapy as a possible future therapeutic strategy in CHF in a double-blind randomized controlled trial.

\section{References}

1. Braunwald E. Heart failure. JACC Heart Fail 2013;1:1-20.

2. Salzano A, Sirico D, Arcopinto M, et al. [Anti remodeling therapy: new strategies and future perspective in post-ischemic heart failure. Part II]. Monaldi Arch Chest Dis 2014;82:195-201. [Article in Italian].

3. Sirico D, Salzano A, Celentani D, et al. [Anti remodeling therapy: new strategies and future perspective in post-ischemic heart failure: Part I[. Monaldi Arch Chest Dis. 2014;82:187-94. [Article in Italian].

4. Cittadini A, Monti MG, Iaccarino G, et al. SOCS1 gene transfer accelerates the transition to heart failure through the inhibition of the gp130/JAK/STAT pathway. Cardiovasc Res 2012;96:381-90.

5. Hartupee J, Mann DL. Neurohormonal activation in heart failure with reduced ejection fraction. Nat Rev Cardiol.2016;14:30-8.

6. Ponikowski P, Voors AA, Anker SD, et al. 2016 ESC Guidelines for the diagnosis and treatment of acute and chronic heart failure. Eur J Heart Fail 2016;18:891-975.

7. Sacca L. Heart failure as a multiple hormonal deficiency syndrome. Circ Hear Fail 2009;2:151-1.

8. Arcopinto M, Salzano A, Ferrara F, et al. The Tosca Registry: An Ongoing, observational, multicenter registry for chronic heart failure. Transl Med @ UniSa 2016;14:21-7.

9. Cittadini A, Bossone E, Marra AM, et al. [Anabolic/catabolic imbalance in chronic heart failure]. Monaldi Arch Chest Dis 2010;74:53-6. [Article in Italian].

10. Arcopinto M, Bobbio E, Bossone E, et al. The GH/IGF-1 axis in chronic heart failure. Endocr Metab Immune Disord Drug Targets 2013;13:76-91.

11. Marra AM, Arcopinto M, Bossone E, et al. Pulmonary arterial hypertension-related myopathy: an overview of current data and future perspectives. Nutr Metab Cardiovasc Dis 2015;25:131-9.

12. Melmed S. New therapeutic agents for acromegaly. Nat Rev Endocrinol 2016;12:90-8.

13. Kargi AY, Merriam GR. Diagnosis and treatment of growth hormone deficiency in adults. Nat Rev Endocrinol 2013;9335-45.

14. Cittadini A, Monti MG, Castiello MC, et al. Insulin-like growth factor-1 protects from vascular stenosis and accelerates reendothelialization in a rat model of carotid artery injury. $\mathrm{J}$ Thromb Haemost 2009;7:1920-8.

15. Marra AM, Egenlauf B, Ehlken N, et al. Change of right heart size and function by long-term therapy with riociguat in patients with pulmonary arterial hypertension and chronic thromboembolic pulmonary hypertension. Int J Cardiol 2015;195:19-26.

16. Isgaard J, Arcopinto M, Karason K, Cittadini A. GH and the cardiovascular system: an update on a topic at heart. Endocrine 2015;48:25-35.

17. Cittadini A, Monti MG, Iaccarino G, et al. Adenoviral gene transfer of Akt enhances myocardial contractility and intracellular calcium handling. Gene Ther 2006;13:8-19.

18. Broglio F, Benso A, Gottero C, et al. Patients with dilated cardiomyopathy show reduction of the somatotroph responsiveness to GHRH both alone and combined with arginine. Eur J Endocrinol 2000;142:157-63. 
19. Cittadini A, Saldamarco L, Marra AM, et al. Growth hormone deficiency in patients with chronic heart failure and beneficial effects of its correction. J Clin Endocrinol Metab 2009;94:3329-36.

20. Marra AM, Bobbio E, D'Assante R, et al. Growth Hormone as Biomarker in Heart Failure. Heart Fail Clin 2018;14:65-74.

21. Jankowska EA, Biel B, Majda J, et al. Anabolic deficiency in men with chronic heart failure: prevalence and detrimental impact on survival. Circulation 2006;114:1829-37.

22. Niebauer J, Pflaum CD, Clark AL, et al. Deficient insulin-like growth factor I in chronic heart failure predicts altered body composition, anabolic deficiency, cytokine and neurohormonal activation. J Am Coll Cardiol 1998;32:393-7.

23. Arcopinto M, Isgaard J, Marra AM, et al. IGF-1 predicts survival in chronic heart failure. Insights from the T.O.S.CA. (Trattamento Ormonale Nello Scompenso CArdiaco) registry. Int J Cardiol 2014;176:1006-8.

24. Anker SD, Volterrani M, Pflaum CD, et al. Acquired growth hormone resistance in patients with chronic heart failure: implications for therapy with growth hormone. J Am Coll Cardiol 2001;38:443-52.

25. Wang C-Y, Chung H-W, Cho N-Y, et al. Idiopathic growth hormone deficiency in the morphologically normal pituitary gland is associated with perfusion delay. Radiology 2011;258:213-21.

26. Rosenkranz S, Gibbs JSR, Wachter R, et al. Left ventricular heart failure and pulmonary hypertension $\dagger$. Eur Heart J 2016;37:942-54.

27. Marra AM, Bossone E, Salzano A, et al. Biomarkers in pulmonary hypertension. Heart Fail Clin 2018;14:393-402.

28. Yoshida T, Tabony AM, Galvez S, et al. Molecular mechanisms and signaling pathways of angiotensin II-induced muscle wasting: Potential therapeutic targets for cardiac cachexia. Int J Biochem Cell Biol 2013;45:2322-32.

29. Giustina A, Veldhuis JD. Pathophysiology of the neuroregulation of growth hormone secretion in experimental animals and the human. Endocr Rev 1998;19:717-97.

30. Doehner W, Rauchhaus M, Ponikowski P, et al. Impaired insulin sensitivity as an independent risk factor for mortality in patients with stable chronic heart failure. J Am Coll Cardiol 2005;46:1019-26.

31. Marra AM, Arcopinto M, Salzano A, et al. Detectable interleukin-9 plasma levels are associated with impaired cardiopulmonary functional capacity and all-cause mortality in patients with chronic heart failure. Int J Cardiol 2016;209:114-17.

32. Saccà F, Piro R, De Michele G, et al. Epoetin alfa increases frataxin production in Friedreich's ataxia without affecting hematocrit. Mov Disord 2011;26:739-42.

33. Bossone E, Savarese G, Ferrara F, et al. Takotsubo cardiomyopathy. Heart Fail Clin 2013;9:249-66.

34. Marra AM, Improda N, Capalbo D, et al. Cardiovascular abnormalities and impaired exercise performance in adolescents with congenital adrenal hyperplasia. J Clin Endocrinol Metab 2015;100:644652.

35. Bossone E, Lyon A, Citro R, et al. Takotsubo cardiomyopathy: an integrated multi-imaging approach. Eur Hear J - Cardiovasc Imaging 2014;15:366-77.

36. Colao A, Di Somma C, Cuocolo A, et al. The severity of growth hormone deficiency correlates with the severity of cardiac impairment in 100 adult patients with hypopituitarism: an observational, case-control study. J Clin Endocrinol Metab 2004;89:5998-6004.

37. Arcopinto M, Salzano A, Giallauria F, et al. Growth hormone deficiency is associated with worse cardiac function, physical performance, and outcome in chronic heart failure: Insights from the T.O.S.CA. GHD Study. PLoS One 2017;12:e0170058.
38. Grünig E, Biskupek J, D'andrea A, et al. Reference ranges for and determinants of right ventricular area in healthy adults by twodimensional echocardiography. Respiration 2015;89:284-93.

39. Naeije R, Saggar R, Badesch D, et al. Exercise-induced pulmonary hypertension: Translating pathophysiological concepts into clinical practice. Chest 2018;154:10-5.

40. Ferrara F, Gargani L, Ostenfeld E, et al. Imaging the right heart pulmonary circulation unit: Insights from advanced ultrasound techniques. Echocardiography 2017;34:1216-31.

41. Marra AM, Benjamin N, Ferrara F, et al. Reference ranges and determinants of right ventricle outflow tract acceleration time in healthy adults by two-dimensional echocardiography. Int J Cardiovasc Imaging 2017;33:219-26.

42. Ferrara F, Gargani L, Ruohonen S, et al. Reference values and correlates of right atrial volume in healthy adults by two-dimensional echocardiography. Echocardiography 2018. doi: 10.1111/echo.14015. [Epub ahead of print].

43. Marra AM, Naeije R, Ferrara F, et al. Reference ranges and determinants of tricuspid regurgitation velocity in healthy adults assessed by two-dimensional doppler-echocardiography. Respiration 2018:1-9. doi: 10.1159/000490191. [Epub ahead of print]

44. Ferrara F, Gargani L, Armstrong WF, et al. The Right Heart International Network (RIGHT-NET): Rationale, objectives, methodology, and clinical implications. Heart Fail Clin 2018;14:443-56.

45. Bhandari SS, Narayan H, Jones DJL, et al. Plasma growth hormone is a strong predictor of risk at 1 year in acute heart failure. Eur J Heart Fail 2016;18:281-9.

46. Broglio F, Fubini A, Morello M, et al. Activity of GH/IGF-I axis in patients with dilated cardiomyopathy. Clin Endocrinol (Oxf) 1999;50:417-30.

47. Al-Obaidi MK, Hon JKF, Stubbs PJ, et al. Plasma insulin-like growth factor-1 elevated in mild-to-moderate but not severe heart failure. Am Heart J 2001;142:11A-5.

48. Watanabe $\mathrm{S}$, Tamura T, Ono $\mathrm{K}$, et al. Insulin-like growth factor axis (insulin-like growth factor-I/insulin-like growth factor-binding protein-3) as a prognostic predictor of heart failure: association with adiponectin. Eur J Heart Fail 2010;12:1214-22.

49. Petretta M, Colao A, Sardu C, et al. NT-proBNP, IGF-I and survival in patients with chronic heart failure. Growth Horm IGF Res 2007;17:288-96.

50. Salzano A, Marra AM, Ferrara F, et al. Multiple hormone deficiency syndrome in heart failure with preserved ejection fraction. Int J Cardiol 2016;225:1-3.

51. Proietti M, Marra AM, Tassone EJ, et al. Frequency of left ventricular hypertrophy in non-valvular atrial fibrillation. Am J Cardiol 2015;116:877-82.

52. Costantino G, Podda GM, Falsetti L, et al. Guidelines on the management of atrial fibrillation in the emergency department: a critical appraisal. Intern Emerg Med 2017;12:693-703.

53. Yang R, Bunting S, Gillett N, et al. Growth hormone improves cardiac performance in experimental heart failure. Circulation 1995;92:262-67.

54. Duerr RL, McKirnan MD, Gim RD, et al. Cardiovascular effects of insulin-like growth factor-1 and growth hormone in chronic left ventricular failure in the rat. Circulation 1996;93:2188-96.

55. Ryoke T, Gu Y, Mao L, et al. Progressive cardiac dysfunction and fibrosis in the cardiomyopathic hamster and effects of growth hormone and angiotensin-converting enzyme inhibition. Circulation 1999;100:1734-43.

56. Cittadini A, Grossman JD, Napoli R, et al. Growth hormone attenuates early left ventricular remodeling and improves cardiac function in rats with large myocardial infarction. J Am Coll Cardiol 1997;29:1109-16. 
57. Fazio S, Sabatini D, Capaldo B, et al. A preliminary study of growth hormone in the treatment of dilated cardiomyopathy. N Engl J Med 1996;334:809-14.

58. Genth-Zotz S, Zotz R, Geil S, et al. Recombinant growth hormone therapy in patients with ischemic cardiomyopathy: effects on hemodynamics, left ventricular function, and cardiopulmonary exercise capacity. Circulation 1999;99:18-21.

59. Spallarossa P, Rossettin P, Minuto F, et al. Evaluation of growth hormone administration in patients with chronic heart failure secondary to coronary artery disease. Am J Cardiol 1999;84:430-3.

60. Perrot A, Ranke MB, Dietz R, Osterziel KJ. Growth hormone treatment in dilated cardiomyopathy. J Card Surg 16:127-31.

61. Napoli R, Guardasole V, Matarazzo M, et al. Growth hormone corrects vascular dysfunction in patients with chronic heart failure. J Am Coll Cardiol 2002;39:90-5.

62. Acevedo M, Corbalán R, Chamorro G, et al. Administration of growth hormone to patients with advanced cardiac heart failure: effects upon left ventricular function, exercise capacity, and neurohormonal status. Int J Cardiol 2003;87):185-91.

63. Fazio S, Palmieri EA, Affuso F, et al. Effects of growth hormone on exercise capacity and cardiopulmonary performance in patients with chronic heart failure. J Clin Endocrinol Metab 2007;92:4218-23.

64. Isgaard J, Bergh $\mathrm{CH}$, Caidahl $\mathrm{K}$, et al. A placebo-controlled study of growth hormone in patients with congestive heart failure. Eur Heart J 1998;19:1704-11.

65. Arcopinto M, Salzano A, Isgaard J, Cittadini A. Hormone replacement therapy in heart failure. Curr Opin Cardiol 2015;30:277-84.

66. Cittadini A, Marra AM, Arcopinto M, et al. Growth hormone replacement delays the progression of chronic heart failure combined with growth hormone deficiency: An extension of a randomized controlled single-blind study. JACC Hear Fail 2013;1325:30.

67. Pasquali D, Arcopinto M, Renzullo A, et al. Cardiovascular abnormalities in Klinefelter syndrome. Int J Cardiol 2013;168:754-9.

68. Marra AM, Arcopinto M, Bobbio E, et al. An unusual case of dilated cardiomyopathy associated with partial hypopituitarism. Intern Emerg Med 2012;7(Suppl 2):S85-7.

69. Salzano A, Arcopinto M, Marra AM, et al. Klinefelter syndrome, cardiovascular system, and thromboembolic disease: review of literature and clinical perspectives. Eur J Endocrinol 2016;175:R27-40.

70. Mosca S, Paolillo S, Colao A, et al. Cardiovascular involvement in patients affected by acromegaly: An appraisal. Int J Cardiol 2013;167:1712-8.

71. Salzano A, Demelo-Rodríguez P, Marra AM, et al. A focused review of gender differences in antithrombotic therapy. Curr Med Chem 2017;24:2576-88.
72. Marra AM, Benjamin N, Eichstaedt C, et al. Gender-related differences in pulmonary arterial hypertension targeted drugs administration. Pharmacol Res 2016;114:103-9.

73. Di Giosia P, Passacquale G, Petrarca M, et al. Gender differences in cardiovascular prophylaxis: Focus on antiplatelet treatment. Pharmacol Res 2017;119:36-47.

74. Cittadini A, Bossone E, Marra AM, et al. [Anabolic/catabolic imbalance in chronic heart failure]. Monaldi Arch Chest Dis 2015;74:53-6. [Article in Italian].

75. Giannoulis MG, Boroujerdi MA, Powrie J, et al. Gender differences in growth hormone response to exercise before and after rhGH administration and the effect of rhGH on the hormone profile of fit normal adults. Clin Endocrinol (Oxf) 2005;62:315-22.

76. Marra AM, Biskup E, Raparelli V. The Internal Medicine and Assessment of Gender Differences in Europe (IMAGINE): The new European Federation of Internal Medicine initiative on sex and gender medicine. Eur J Intern Med 2018;51:e30-2.

77. Bossone E, Arcopinto M, Iacoviello M, et al. Multiple hormonal and metabolic deficiency syndrome in chronic heart failure: Rationale, design, and demographic characteristics of the T.O.S.CA. Registry. Intern Emerg Med 2018;13:661-71

78. Bossone E, Limongelli G, Malizia G, et al. The T.O.S.CA. Project: Research, education and care. Monaldi Arch Chest Dis 2011;76:198-203.

79. Andreassen M, Kistorp C, Raymond I, et al. Plasma insulin-like growth factor I as predictor of progression and all cause mortality in chronic heart failure. Growth Horm IGF Res. 2009;19(6):486-490.

80. Faxén UL, Hage C, Benson L, et al. HFpEF and HFrEF display different phenotypes as assessed by IGF-1 and IGFBP-1. J Card Fail 2017;23:293-303.

81. Frustaci A, Gentiloni N, Russo MA. Growth hormone in the treatment of dilated cardiomyopathy. N Engl J Med 1996;335:672-4.

82. Osterziel KJ, Strohm 0, Schuler J, et al. Randomised, double-blind, placebo-controlled trial of human recombinant growth hormone in patients with chronic heart failure due to dilated cardiomyopathy. Lancet 1998;351:1233-7.

83. Jose VJ, Zechariah TU, George P, Jonathan V. Growth hormone therapy in patients with dilated cardiomyopathy: preliminary observations of a pilot study. Indian Heart J. 51:183-5.

84. Hatton N, Frech T, Smith B, et al. Transforming growth factor signalling: a common pathway in pulmonary arterial hypertension and systemic sclerosis. Int J Clin Pract 2011;65:35-43.

85. Adamopoulos S, Parissis JT, Paraskevaidis I, et al. Effects of growth hormone on circulating cytokine network, and left ventricular contractile performance and geometry in patients with idiopathic dilated cardiomyopathy. Eur Heart J 2003;24:2186-96. 